\title{
Ulaşım Sektöründeki İşletmelerin Finansal Performanslarının Geliştirilmiş Entropi Temelli TOPSIS Yöntemi ile Değerlendirilmesi
}

\author{
Şakir SAKARYA*, Melek AKSU**
}

ÖZ

$\mathrm{Bu}$ çalı̧̧mada ulaştırma sektöründe faaliyet gösteren ve Borsa İstanbul (BIST)'da işlem gören işletmelerin 2013-2017 yılları arasındaki finansal performansları on dört finansal oran aracıllı̆gyla çok kriterli karar verme yöntemlerinden biri olan TOPSIS yöntemi ile değerlendirilmiştir. Değerlendirme kriteri olarak kullanılan finansal oranların ağırlıklarının belirlenmesinde subjektiviteden kaçınmak için geliştirilmiş Entropi yöntemi kullanılmıştır. Çalışmanın sonucunda; 2013 yılından 2017 yılına kadar en başarılı firmalar sırasıyla RYSAS, CLEBI, CLEBI, BEYAZ ve CLEBI olmuştur. Finansal açıdan en başarısız olan işletmeler ise sırasıyla THYAO, BEYAZ, RYSAS, PGSUS ve THYAO olmuştur. Ayrıca işletmelerin finansal performans sıralamaları hisse getiri sıralamaları ile karşılaştırılmış ve finansal açıdan başarılı olduğu tespit edilen işletmelerin her zaman en yüksek hisse getirisine sahip olmadığı anlaşılmıştır.

Anahtar Kelimeler: Finansal Performans Analizi, Ulaşım Sektörü, TOPSIS, Geliştirilmiş Entropi

JEL Sinıflandırması: C44, D81

\section{Financial Performance Ranking of Transportation Companies with TOPSIS Based on Improved Entropy Method}

\begin{abstract}
This paper aims to evaluate financial performance ranking of companies operate in transportation sector and listed on Borsa Istanbul (BIST) between the years of 2013 and 2017 via TOPSIS which is a multiple criteria decision making method. In this paper, fourteen financial ratios are used to evaluate financial performances of companies. The improved entropy method is used to determine the weights of financial ratios. The financial performance of RYSAS, CLEBI, CLEBI, BEYAZ and CLEBI has the highest TOPSIS score, while the financial performance of THYAO, BEYAZ, RYSAS, PGSUS and THYAO has the lowest score between the years of 2013 and 2017. The comparison of financial performance and stock return rankings of companies shows that the companies that have the highest financial performance do not always have the highest stock return.
\end{abstract}

Keywords: Financial Performance Analysis, Transportation Sector, TOPSIS, Improved Entropy

JEL Classification: C44, D81

Geliş Tarihi / Received: 20.02.2019 Kabul Tarihi / Accepted: 12.07.2019

\footnotetext{
*Prof. Dr., Balıkesir Üniversitesi, İİBF, İşletme Bölümü, sakarya@ balikesir.edu.tr, ORCID: 0000-0003-2510-7384.

** Arş. Gör., Balıkesir Üniversitesi, İ̈BF, İşletme Bölümü, maksu@ balikesir.edu.tr, ORCID: 0000-0003-2906-1117.
} 


\section{GİRIŞ}

Ulaşım sektörü ekonomik kalkınmanın sağlanmasında önemli rolü olan bir sektördür (Erdoğan, 2016:189). Bu nedenle ulaşım sektöründe faaliyet gösteren işletmelerin finansal ve operasyonel performansları faaliyet gösterdikleri ülkeler açısından büyük önem teşkil etmektedir. Küreselleşme ile birlikte ulaşım sektörünün dünya pazarındaki öneminin hızla artmasıyla birlikte ulaşım sektöründe faaliyet gösteren işletmeler arasındaki rekabet de önemli boyutlara ulaşmıştır. Günümüz küresel ekonomisinde, giderek artan uluslararası rekabet koşullarında işletmelerin rekabet üstünlüğü elde edebilmesi maliyetlerini kontrol altında tutarak finansal performanslarını iyileştirme çabalarının sonucunda mümkün olmaktadır (Başdeğirmen ve Iş̧1lak, 2018:575). İşletmelerin finansal performanslarını iyileştirebilmesi ise finansal performanslarını değerlendirebilmeleri ile mümkün olabilmektedir. Finansal performans değerlendirmeleri; hem işletmelerin yatırım ve finansman kararlarındaki etkinliklerini değerlendirme hem de sektörde yer alan diğer işletmelerle kendi durumlarını kıyaslama imkânı sağlamaktadır. Finansal performansın yüksek olması işletmelerin finansal açıdan sağlıklı olduğu anlamına da gelebilmektedir. Yüksek finansal performans sergileyen işletmeler yatırımcılar açısından cazip hale gelecek ve işletmede hissedarların refahını maksimize etme amacına ulaşılmış olunacaktır.

Ülkeler açısından büyük önem taşıyan ulaştırma sektöründe faaliyet gösteren işletmelerin finansal performanslarının değerlendirilmesi bu sektörde çalışanlar, mevcut ve potansiyel yatırımcılar ve yeni kurulacak işletmeler açısından önemlidir. Ayrıca ülke ekonomisinde önemli bir etkiye sahip ulaştırma sektörünün temsilcileri konumunda olan işletmelerin finansal performanslarının çok boyutlu bir perspektifle değerlendirilmesi bu işletmelerin finansal yol haritasının hazırlanmasına destek olmaktadır. Bu bağlamda çalışmanın sektöre, sektör temsilcilerine ve yatırımcıların yatırım kararlarına katkı sağlayacağı düşünülmektedir.

Bu çalışmada ekonomik kalkınmada önemli bir rolü olan ulaşım sektöründe faaliyet gösteren 2017 yılında yayımlanan (Capital-2016) Türkiye'nin en büyük 500 şirketi arasında yer alan halka açık beş ulaşım işletmesinin 2013-2017 yılları arasındaki finansal performanslarının değerlendirilerek karşılaştırılması amaçlanmaktadır. Çok kriterli karar verme (ÇKKV) yöntemlerinin finansal analizde güvenilirliği artırması (Esbouei, Ghadikolaei ve Antucheviciene, 2014:288) nedeniyle çalışmanın kapsamını oluşturan işletmelerin finansal performanslarının değerlendirilmesinde TOPSIS (Technique for Order Preference by Similarity to Ideal Solution) yönteminden yararlanılmıştır. TOPSIS yönteminde işletmelerin finansal performanslarının değerlendirilmesinde kullanılan finansal oranların ağırlıklarının belirlenmesi için geliştirilmiş Entropi yöntemi kullanılmıştır. Ulusal literatürde ulaştırma sektöründe faaliyet gösteren işletmelerin finansal performanslarının değerlendirildiği çalışmaların kısıtlı olması ve finansal performanslarının değerlendirilmesinde kullanılan finansal kriterlerin önem derecelerinin belirlenmesinde sıklıkla subjektif yöntemlerden yararlanılması nedeniyle çalışmanın literatüre katk1 sunacağı beklenmektedir.

Çalışmanın giriş bölümünün ardından ikinci bölümde literatürde yer alan ulaşım, lojistik ve depolama şirketlerinin finansal performanslarını çok kriterli karar verme yöntemlerini kullanarak değerlendiren çalışmalara, üçüncü bölümde çalışmanın amaç, kapsam ve yönteminin ele alındığ̣ yöntem bölümüne, dördüncü bölümde çalışmanın bulgularına yer verilmiştir. Beşinci ve son bölüm çalışmanın sonuç bölümüdür.

\section{LITERATÜR}

İşletmelerin finansal performanslarının değerlendirilmesi ve karşılaştırılabilmesi için finansal oranlardan yararlanılmaktadır. Birden fazla finansal oranın bir arada 
değerlendirilebilmesi ise ÇKKV yöntemleri ile mümkün olmaktadır. Çalışmanın bu bölümünde çalışmanın kapsamını oluşturan ulaşım sektörü işletmelerinin finansal performanslarının ÇKKV yöntemleri ile değerlendirildiği çalışmalar incelenmiştir.

Feng ve Wang (2000), Tayvan'da faaliyet gösteren beş havayolu işletmesinin finansal performansını TOPSIS yöntemi ile karşılaştırmış, TOPSIS yönteminin uygulanması için kullanılacak finansal oranları Gri İlişsisel Analiz yöntemi ile belirlemişlerdir.

Chang, Cheng ve Wang (2003), Doğu Asya bölgesinde 10 havayolu işletmesinin performanslarını değerlendirmeyi amaçlamıştır. Çalışmada havayolu işletmelerinin performanslarını ölçülebilmesi için gerekli olan kriterlerin seçiminde Gri İlişkisel Analiz Yöntemi, kriter ağırlıklarının belirlenmesinde Bulanık Analitik Hiyerarşi Süreci ve havayolu işletmelerinin finansal performanslarının değerlendirilmesi aşamasında ise TOPSIS yöntemi kullanılmıştır.

Wang (2008), Tayvan'da faaliyet gösteren üç havayolu işletmesinin finansal performansını bulanık TOPSIS yöntemi ile karşılaştırmışlardır.

Korkmaz ve Uygurtürk (2010), Amerika'da denizyolu taşımacıllı̆̆ sektöründe faaliyet gösteren ve hisseleri borsada işlem gören 20 işletmenin finansal performansını 2008-2010 yılları arasında cari oran, likidite oranı, sabit aktif devir hızı, toplam aktif devir hızı, borç-toplam aktif oran1, net kar marjı, özsermaye karlılığı değerlendirme kriterleri ile TOPSIS yöntemini uygulayarak karşılaştırmışlardır.

Ömürbek ve Kınay (2013), BIST’te faaliyet gösteren bir havayolu taşımacıllı̆̆1 şirketi ile Frankfurt Menkul Kıymetler Borsası'nda faaliyet gösteren bir havayolu taşımacılığ 1 şirketinin finansal performanslarını TOPSIS yöntemi ile karşılaştırmışlardır. Karşılaştırmada kullandıkları kriterlerin ağırlıklarını literatür taraması aracılı̆̆1 ve sektörde muhasebe finansman departmanında çalışan uzman ve üniversitelerin muhasebe finansman anabilim dalında görev yapmakta olan öğretim üyelerinden oluşan uzman kişilerle görüşerek belirlemişlerdir.

Wang (2014), konteyner taşımacılık şirketlerinin finansal performanslarını bulanık TOPSIS yöntemi ile yirmi bir tane finansal orandan yararlanarak değerlendirmiştir.

Akgün ve Soy Temür (2016), BIST ulaştırma endeksine kayıtlı iki havayolu taşımacılığı şirketinin 2010-2015 dönemini kapsayan 6 yıllık dönemde finansal performansını değerlendirmek amacıyla TOPSIS yöntemini kullanmışlardır. Çalışmada üç likidite, beş finansal yapı, iki faaliyet, iki karlılık oranı olmak üzere toplamda on iki finansal oran ve her oran grubu için eşit ağırlık kullanılmıştır.

Kendirli ve Kaya (2016) çalışmalarında BIST Ulaştırma Endeksinde yer alan işletmeleri finansal performansları açısından dört likidite, altı finansal yapı, beş faaliyet, üç karlılık oranı kullanarak ve her oran grubuna eşit ağırlık vererek TOPSIS yöntemiyle sıralamışlardır.

Ayaydın, Durmuş ve Pala (2017), verimlilik, büyüklük ve karlılık oranları yardımıyla 2011 yılı için FORTUNE dergisinin açıkladığı ilk 500 firma listesinde yer alan 10 lojistik firmasının performansını GİA yöntemi ile her bir değerlendirme kriterine eşit ağırlık vererek değerlendirmiştir.

Başdeğirmen ve Tunca (2017), 2016 y1lında Capital Dergisi’nin yayınlamış olduğu “İlk 500 Büyük İşletme" sıralamasındaki dokuz lojistik işletmesinin finansal performansını ciro, ihracat, vergi öncesi kar, çalışan sayısı, toplam aktif ve özsermaye değerlendirme kriterlerini kullanarak Gri İlişkisel Analiz yöntemi ile değerlendirip karşılaştırmışlardır. İşletmelerin finansal performansları karşılaştırılırken değerlendirme kriterlerine ilk olarak eşit ağırlık daha sonra da uzman görüşleri doğrultusunda farklı ağırlıklar verilmiştir. 
Başdeğirmen ve Ișıldak (2018), Başdeğirmen ve Tunca (2017)'nın çalışması doğrultusunda 2016 yılında Capital Dergisi'nin yayınlamış olduğu "İlk 500 Büyük İşletme" listesinde yer alan ve ulaştırma sektöründe faaliyet gösteren sekiz işletmenin finansal performansını değerlendirmiştir.

Özbek ve Demirkol (2018), Fortune 500 listesinde yer alan sekiz lojistik firmasının 2016 yılındaki ekonomik performansını net satış, net satış değişimi, faiz, vergi öncesi kar, FVÖK değişimi, toplam aktif, özkaynak, ihracat ve çalışan sayısı kriterlerine göre çok kriterli karar verme yöntemlerinden GİA ile değerlendirmiştir. Özbek ve Demirkol'un çalışmalarında kriter ağırlıkları çok kriterli karar verme yöntemlerinden SWARA ile belirlenmiştir.

Kiracı ve Bakır (2018) çalışmalarında 2012-2016 dönemi için Entropi temelli TOPSIS yöntemi kullanarak on tane finansal oran aracıllı̆ıyla yolcu sayısı bakımından en büyük 10 havayolu şirketinin finansal performansını değerlendirmişlerdir.

Gümüş, Öziç, Evlimoğlu ve Sezer (2018) çalışmalarında ulaşım sektöründe yer alan işletmelerin 2013-2015 arasındaki finansal performanslarını AHP ve TOPSIS yöntemleri ile değerlendirmişlerdir.

Yıldırım (2018), 2005-2017 yılları arasında BIST’te işlem gören lojistik işletmelerinin performansını TOPSIS yöntemi ile değerlendirdiği tezinde değerlendirme kriterlerine eşit ağırlık ve lojistik sektöründe muhasebe finansman departmanında çalışan uzman, uzman yardımcıları ve üniversitelerin muhasebe ve finansman anabilim dalında görev yapan öğretim görevlilerinden oluşan kişilerce belirlenen farklı ağırlıklar vermiştir.

\section{YÖNTEM}

\section{1. Çalışmanın Amacı, Kapsamı ve Veri Seti}

$\mathrm{Bu}$ çalışmanın amacı ekonomik kalkınmanın sağlanmasında önemli bir rolü olan ulaştırma sektöründe faaliyet gösteren işletmelerin finansal performanslarının değerlendirilmesi ve sıralanmasıdır. Çalışmanın kapsamını ulaştırma sektöründe faaliyet gösteren, BIST’te işlem gören ve 2017 yılında yayımlanan (Capital-2016) Türkiye'nin en büyük 500 şirketi arasında yer alan beş işletme oluşturmaktadır. Çalışmanın kapsamını oluşturan işletmeler Tablo 1'de gösterilmiştir.

Tablo 1: Performansı Ölçümlenen İşletmelerin Listesi

\begin{tabular}{ccl}
\hline Sıra No & BIST İşlem Kodu & İşletme Unvanı \\
\hline $\mathbf{1}$ & BEYAZ & Beyaz Filo Oto Kiralama A.Ş. \\
\hline $\mathbf{2}$ & CLEBI & Çelebi Hava Servisi A.Ş. \\
\hline $\mathbf{3}$ & PGSUS & Pegasus Hava Taşımacılığı A.Ş. \\
\hline $\mathbf{4}$ & RYSAS & Reysaş Taşımacılık ve Lojistik A.Ş. \\
\hline $\mathbf{5}$ & THYAO & Türk Hava Yolları A.O \\
\hline
\end{tabular}


Performans1 değerlendirilen beş ulaşım işletmesinin finansal performansının ölçülmesinde; likidite, finansal, faaliyet, karlılık ve büyüme yapıları hakkında bilgi veren finansal oranlardan yararlanılmıştır. Ulaşım işletmelerinin finansal performanslarının değerlendirilmesinde kullanılan oranların belirlenmesinde büyük oranda Yıldırım (2018)'ın çalışmasından yararlanılmıştır. Analizde kullanılan finansal oranlar ve çalışmanın diğer kısımlarında oranları temsilen kullanılacak olan kodlar oranların formülleriyle birlikte Tablo 2'de gösterilmiştir. İşletmelerin 2013-2017 yıllarına ait finansal oranları Finnet Analiz Expert veri tabanından elde edilmiştir.

Tablo 2: Çalışmada Kullanılan Finansal Oranlar

\begin{tabular}{|c|c|c|c|}
\hline $\begin{array}{c}\text { Oran } \\
\text { Grubu }\end{array}$ & Kullanılan Oranlar & Kod & Formül \\
\hline \multirow{2}{*}{ Likidite } & Cari Oran & $\mathrm{L}_{1}$ & Dönen Varlıklar/Kısa Vadeli Borçlar \\
\hline & Likit Oran & $\mathrm{L}_{2}$ & Likit Varlıklar / Kısa Vadeli Yükümlülükler \\
\hline \multirow{3}{*}{$\begin{array}{c}\text { Finansal } \\
\text { Yapı }\end{array}$} & $\begin{array}{l}\text { Finansal Kaldıraç } \\
\text { Oranı }\end{array}$ & $\mathrm{M}_{1}$ & Toplam Borç / Toplam Varlık \\
\hline & $\begin{array}{l}\text { Toplam } \\
\text { Borç/Özsermaye }\end{array}$ & $\mathrm{M}_{2}$ & Toplam Borç / Özsermaye \\
\hline & $\begin{array}{l}\text { Maddi Duran } \\
\text { Varlık/Özsermaye } \\
\end{array}$ & $\mathrm{M}_{3}$ & Maddi Duran Varlık / Özsermaye \\
\hline \multirow{3}{*}{ Faaliyet } & Aktif Devir Hızı & $F_{1}$ & Net Satış / Aktifler (ortalama) \\
\hline & Alacak Devir Hızı & $\mathrm{F}_{2}$ & Net Satış / Kısa Vadeli Alacaklar (ortalama) \\
\hline & Özsermaye Devir Hızı & $\mathrm{F}_{3}$ & Net Satış / Özsermaye \\
\hline \multirow{4}{*}{ Karlılık } & Aktif Karlılık Oranı & $\mathrm{K}_{1}$ & (Net Kar / Aktifler (ortalama)) \\
\hline & $\begin{array}{l}\text { Esas Faaliyet Kar } \\
\text { Marj1 }\end{array}$ & $\mathrm{K}_{2}$ & (Esas Faaliyet Kar / Net Satış ) \\
\hline & Net Kar Marji & $\mathrm{K}_{3}$ & Ana Ortaklık Kar Zarar / Net Satış \\
\hline & $\begin{array}{l}\text { Özsermaye Karlılık } \\
\text { Oranı }\end{array}$ & $\mathrm{K}_{4}$ & (Net Kar / Özsermaye (ortalama)) \\
\hline \multirow{2}{*}{ Büyüme } & Aktif Büyüme & $\mathrm{B}_{1}$ & $\begin{array}{l}\text { (Toplam Aktif - Bir yıl önceki Toplam Aktif) / Bir yıl önceki Toplam } \\
\text { Aktif }\end{array}$ \\
\hline & $\begin{array}{l}\text { Esas Faaliyet Kar } \\
\text { Büyüme }\end{array}$ & $\mathrm{B}_{2}$ & $\begin{array}{l}\text { (Esas Faaliyet Kar1 - Bir yıl önceki Esas Faaliyet Karı ) / Bir yı1 } \\
\text { önceki Esas Faaliyet Karı }\end{array}$ \\
\hline
\end{tabular}

\section{2. Çalışmanın Yöntemi}

Çalışmada işletmelerin finansal performanslarının değerlendirilerek sıralamalarının yapılabilmesi için TOPSIS yönteminden yararlanılmıştır. TOPSIS yöntemi işletmelerin finansal performanslarının değerlendirilebilmesi ve karşılaştırılabilmesi için farklı finansal performans göstergelerini birlikte değerlendirebilme imkânı tanımaktadır. TOPSIS yönteminde değerlendirme kriteri olarak kullanılan finansal oranların önem ağırlıkları ise geliştirilmiş Entropi yönteminden yararlanılarak belirlenmiştir. Çalışmanın bu bölümünde TOPSIS yöntemi ve geliştirilmiş Entropi ağırlık belirleme yönteminin aşamaları incelenmektedir.

\subsubsection{Geliştirilmiş Entropi Yöntemi}

Entropi yöntemi karar matrisinin oluşturulmasında kullanılan kriterlerin ağırlıklarının objektif olarak belirlenmesini sağlayan bir yöntemdir. Entropi fizik biliminin yanı sıra sosyal bilimlerde de önem kazanmıştır (Hwang ve Yoon, 1981: 52). Entropi yönteminde kriterlere ilişkin Entropi değerleri hesaplanırken, doğal logaritma fonksiyonu kullanılmaktadır. Karar 
problemine ilişkin karar matrisinde sıfir ya da negatif değerler olması durumunda, logaritmik hesaplamaların yapılması mümkün olmamaktadır. Bu problemin çözümü için Zhang, Wang, Li ve $\mathrm{Xu}$ (2014) tarafindan Z-skoru standartlaştırma dönüşümü kullanılan entropi (improved entropy) yöntemi geliştirilmiştir (Ayçin, 2018: 602-603). Geliştirilmiş entropi yöntemi yedi aşamadan oluşmaktadır ve bu aşamalar aşağıdaki gibidir (Yavuz ve Öztel, 2017:128-129; Zhang, Wang, Li ve $\mathrm{Xu}, 2014: 3$ ).

1. m alternatifli, $n$ kriterli karar matrisi $D\left[x_{i j}\right]_{m \times n}$ oluşturulur. $x_{i j} ;$ i. alternatifin $j$. kritere göre değerlendirilmesidir, $i=1,2, \ldots, m$ ve $j=1,2, \ldots, n$.

2. Karar matrisi verilerin karşılaştırılabilmesi için normalize edilir. Karar matrisinde negatif veri yer alması durumunda öncelikle aşağıda belirtilen Z-skoru normalizasyonu yapilır.

$x_{i j}=\frac{\left(x_{i j}-\bar{X}_{j}\right)}{S_{j}}$

$x_{i j}$ : i. alternatifin $\mathrm{j}$. kritere göre normalize değeri

$X_{i j}:$ karar matrisinde yer alan orijinal veri

$\bar{X}_{j}: \mathrm{j}$. kriterin ortalama değeri

$S_{j}: \mathrm{j}$. kriterin standart sapmas 1

3. Verilerde koordinat dönüşümü yapılır ve karar matrisinde $x_{i j}$ değerleri yerine pozitif dönüşümleri olan $x^{\prime}{ }_{i j}$ değerleri kullanılır.

$x^{\prime}{ }_{i j}=x_{i j}+A, A>\left|\min \left(x_{i j}\right)\right|$

4. Pozitif dönüşümü yapılmış karar matrisi normalize edilir.

$$
P_{i j}=\frac{x^{\prime}{ }_{i j}}{\sum_{i=1}^{m} x^{\prime}{ }_{i j}}
$$

5. Normalize karar matrisinde kriterlerin entropi değerleri hesaplanır.

$$
e_{j}=-k \sum_{i=1}^{m} P_{i j} \ln \left(P_{i j}\right), \quad k=\frac{1}{\ln (m)}, 0 \leq e_{j} \leq 1
$$

6. Kriterlerin farklılaşma dereceleri hesaplanır.

$$
g_{j}=1-e_{j}
$$

7. Kriterlerin ağırlıkları hesaplanır.

$$
w_{j}=\frac{g_{j}}{\sum_{j=1}^{n} g_{j}}
$$

\subsubsection{TOPSIS Yöntemi}

Hwang ve Yoon'un 1980 yılında geliştirdikleri TOPSIS yöntemi seçimi yapılan alternatifin pozitif ideal çözüme en kısa mesafede ve negatif ideal çözümden en uzak mesafede olması gerektiği düşüncesi üzerine kurulmuştur. (Hwang ve Yoon, 1981:128). m alternatifli ( $A_{1}$, $\left.A_{2}, A_{3}, \ldots, A_{m}\right)$, n kriterli $\left(C_{1}, C_{2}, C_{3}, \ldots, C_{n}\right)$ bir problem için TOPSIS yönteminin aşamaları kısaca aşağıdaki gibi sıralanabilir (Salabun, 2013:181):

1. m alternatifli, $n$ kriterli karar matrisi $D\left[x_{i j}\right]_{m \times n}$ oluşturulur. $x_{i j} ; A_{i}$ alternatifinin $C_{j}$ kriterine göre değerlendirilmesidir. 
2. Karar matrisinin normalize edilmesinde çeşitli normalizasyon yöntemleri kullanılmaktadır. Bu çalışmada karar matrisinin normalize edilmesinde aşağıda formülleri verilen vektör normalizasyonundan yararlanılmıştır (Zavadskas ve Turskis, 2008:305; Jahan ve Edwards, 2015:337; Vafaei, Ribeiro ve Camarinha-Matos, 2015:3; Vafaei, Ribeiro ve Camarinha-Matos, 2016:265; Liao, Wu ve Herrera, 2018:66). Vafaei, Ribeiro ve Camarinha-Matos (2015)'un çalışmasında TOPSIS yönteminde verilerin normalize edilmesinde kullanılan vektör normalizasyonu yönteminin en başarılı yöntemler arasında olduğu tespit edilmiştir.

$$
\begin{aligned}
& \text { i. Fayda kriterleri için: } r_{i j}=\frac{x_{i j}}{\sqrt{\sum_{i=1}^{m} x_{i j}^{2}}} \\
& \text { ii. Maliyet kriterleri için: } r_{i j}=1-\frac{x_{i j}}{\sqrt{\sum_{i=1}^{m} x_{i j}^{2}}}
\end{aligned}
$$

3. Ağırlıklı normalize karar matrisi, matrisin her bir elemanı için $v_{i j}=w_{j} . r_{i j}$ şeklinde hesaplanarak oluşturulur.

4. Pozitif ideal $\left(\mathrm{A}^{*}\right)$ ve negatif ideal $\left(\mathrm{A}^{-}\right)$çözümler belirlenir.

$$
\begin{aligned}
& A^{*}=\left\{\left(\max _{i} v_{i j} \mid j \in J\right),\left(\min _{i} v_{i j} \mid j \in J^{\prime}\right\} \quad(\mathrm{i}=1,2, \ldots, \mathrm{m})\right. \\
& A^{*}=\left\{v_{1}^{*}, v_{2}^{*}, \ldots, v_{n}^{*}\right\} \\
& A^{-}=\left\{\left(\min _{i} v_{i j} \mid j \in J\right),\left(\max _{i} v_{i j} \mid j \in J^{\prime}\right\} \quad(\mathrm{i}=1,2, \ldots, \mathrm{m})\right. \\
& A^{-}=\left\{v_{1}^{-}, v_{2}^{-}, \ldots, v_{n}^{-}\right\}
\end{aligned}
$$

5. Öklidyen uzaklıklar hesaplanır:

a. alternatifin en iyi alternatifle arasındaki uzaklık:

$$
S_{i}^{*}=\sqrt{\sum_{j=1}^{n}\left(v_{i j}-v_{j}^{*}\right)^{2}}
$$

b. alternatifin en kötü alternatifle arasındaki uzaklık:

$$
S_{i}^{-}=\sqrt{\sum_{j=1}^{n}\left(v_{i j}-v_{j}^{-}\right)^{2}}
$$

6. İdeal çözüme göreli yakınlık hesaplanır.

$$
\begin{aligned}
& C_{i}^{*}=\frac{S_{i}^{-}}{S_{i}^{-}+S_{i}^{*}}, \quad 0 \leq \mathrm{C}_{\mathrm{i}}^{*} \leq 1 \\
& C_{i}^{*}=1 \text { ilgili karar noktasının ideal çözüme, } C_{i}^{*}=0 \text { ilgili karar noktasının negatif ideal }
\end{aligned}
$$
çözüme mutlak yakınlığını gösterir. 


\section{BULGULAR}

Finansal performansları değerlendirilen beş işletmenin 2013-2017 yılları arasında hesaplanan finansal oranları (değerlendirme kriterleri) ile Tablo 3 'te yer alan $5 \times 14$ boyutlu standart karar matrisi oluşturulmuştur. Karar matrisinde yer alan değerlendirme kriterleri fayda ve maliyet kriterleri olarak ayrılmıştır. Değerlendirme kriterlerinden finansal yapı oranları arasında yer alan Finansal Kaldıraç Oranı $\left(\mathrm{M}_{1}\right)$ ve Toplam Borç/Özsermaye $\left(\mathrm{M}_{2}\right)$ oranları işletmelerde borçlanma maliyetini yükselterek finansal riski artıracağından düşük olması istenmekte ve literatürle uyum (Aytekin ve Erol, 2018; Ege ve Yaman, 2018) açısından $M_{1}$ ve $\mathrm{M}_{2}$ kriterleri maliyet kriteri olarak diğer on iki oran da fayda kriteri olarak değerlendirilmiştir.

Tablo 3: Standart Karar Matrisi

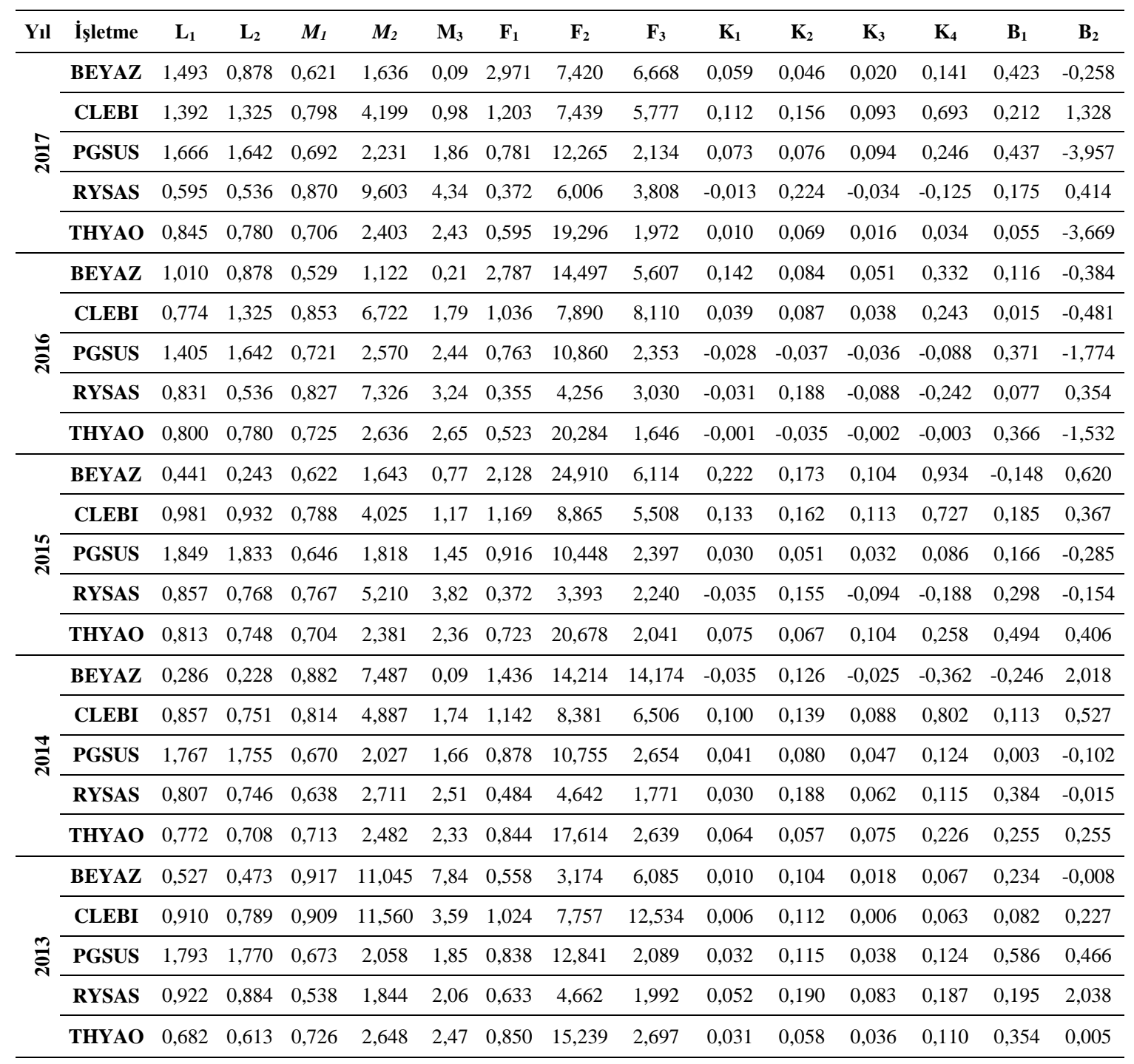

Standart karar matrisinin normalize edilmesinde vektör normalizasyonu yöntemi kullanılmıştır. Standart karar matrisinin vektör normalizasyonu ile normalize edilmiş hali Tablo 4 'te gösterilmektedir. 
Tablo 4: Normalize Karar Matrisi

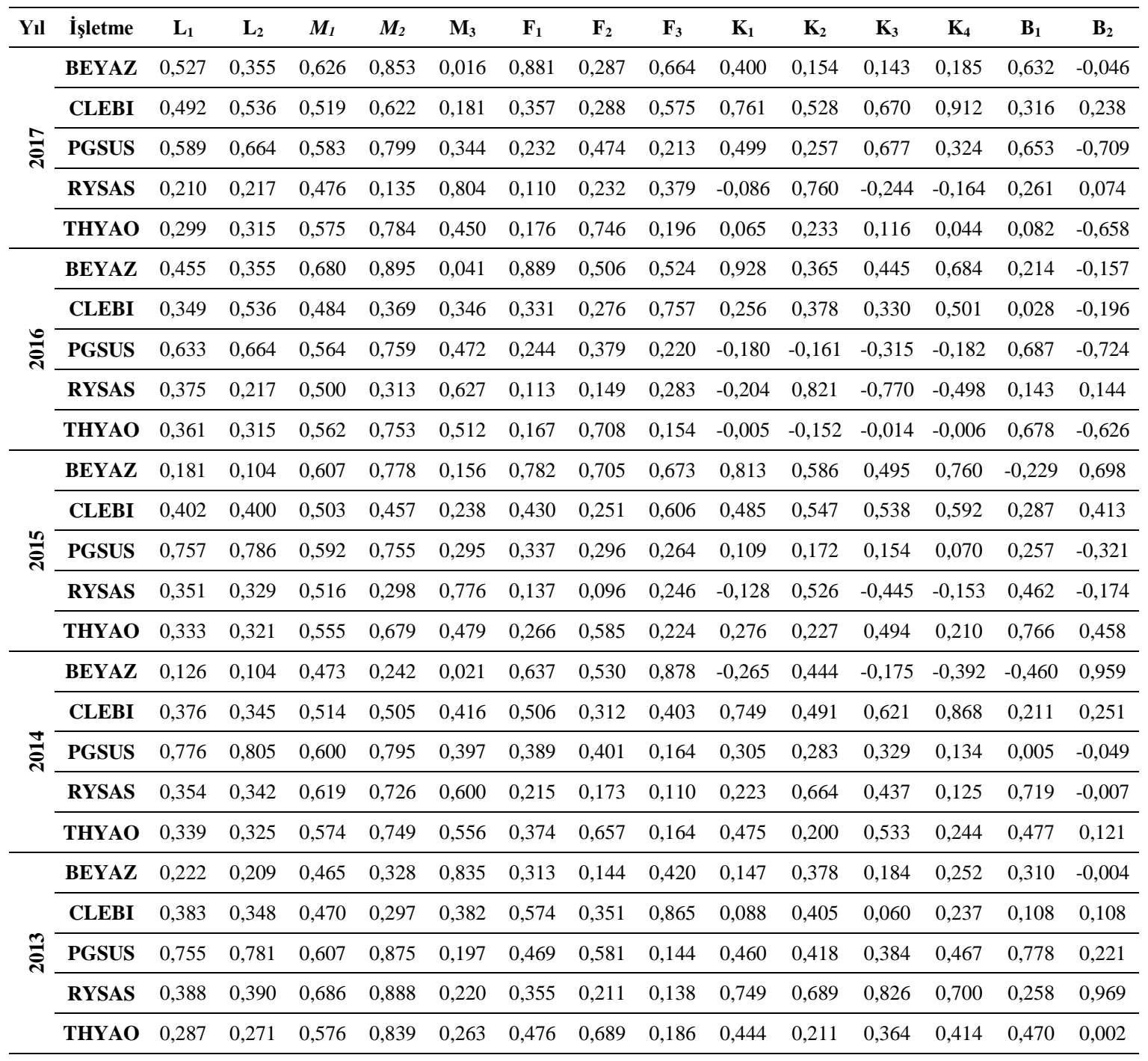

Standart karar matrisinin normalize edilmesinin ardından işletmelerin finansal performanslarının değerlendirilmesinde kullanılan oranların ağırlıklarının objektif değerlendirilebilmesi için geliştirilmiş Entropi yönteminden yararlanılmıştır. Standart karar matrisinde negatif verilerin yer alması nedeniyle öncelikle veriler Z-skoru dönüşümü ve koordinat dönüşümü yapılarak verilerin pozitif dönüşümleri elde edilmiştir. Tablo 5 'te koordinat dönüşümü yapılmış karar matrisi verilmiştir. 
Optimum Journal of Economics and Management Sciences, Vo1. 7, No. 1- http://dergipark.gov.trloptimum

Sakarya and Aksu - Financial Performance Ranking of Transportation Companies with TOPSIS Based on Improved Entropy Method

Tablo 5: Entropi Koordinat Dönüşümü Yapılmış Karar Matrisi

\begin{tabular}{|c|c|c|c|c|c|c|c|c|c|c|c|c|c|c|c|}
\hline Yll & İşletme & $\mathbf{L}_{1}$ & $\mathbf{L}_{2}$ & $M_{1}$ & $M_{2}$ & $\mathbf{M}_{3}$ & $\mathbf{F}_{1}$ & $\mathbf{F}_{2}$ & $\mathbf{F}_{3}$ & $\mathbf{K}_{1}$ & $\mathbf{K}_{2}$ & $\mathbf{K}_{\mathbf{3}}$ & $\mathbf{K}_{4}$ & $\mathbf{B}_{1}$ & $\mathbf{B}_{2}$ \\
\hline \multirow{3}{*}{$\overline{\bar{\gamma}}$} & CLEBI & 1,825 & 2,059 & 2,025 & 1,457 & 0,804 & 1,418 & 0,843 & 2,206 & 2,675 & 1,962 & 2,403 & 3,003 & 1,107 & 2,453 \\
\hline & PGSUS & 2,426 & 2,771 & 0,937 & 0,854 & 1,351 & 1,014 & 1,726 & 0,484 & 1,903 & 0,885 & 2,419 & 1,557 & 2,468 & 0,276 \\
\hline & RYSAS & 0,077 & 0,284 & 2,760 & 3,110 & 2,891 & 0,622 & 0,581 & 1,275 & 0,184 & 2,883 & 0,099 & 0,356 & 0,882 & 2,076 \\
\hline \multirow{3}{*}{$\frac{0}{\overline{0}}$} & BEYAZ & 1,874 & 1,354 & 0,116 & 0,633 & 0,099 & 3,426 & 2,177 & 2,246 & 3,345 & 1,977 & 2,731 & 2,898 & 1,262 & 2,132 \\
\hline & CLEBI & 0,976 & 2,359 & 2,655 & 2,657 & 1,463 & 1,643 & 1,105 & 3,182 & 1,908 & 2,009 & 2,499 & 2,524 & 0,664 & 2,022 \\
\hline & PGSUS & 3,375 & 3,071 & 1,621 & 1,156 & 2,024 & 1,364 & 1,587 & 1,028 & 0,975 & 0,706 & 1,194 & 1,122 & 2,785 & 0,549 \\
\hline \multirow{5}{*}{ 舲 } & BEYAZ & 0,651 & 0,558 & 0,551 & 0,812 & 0,758 & 3,308 & 2,969 & 2,940 & 3,096 & 2,590 & 2,295 & 2,938 & 0,216 & 2,801 \\
\hline & CLEBI & 1,687 & 1,747 & 2,836 & 2,353 & 1,089 & 1,862 & 1,159 & 2,634 & 2,185 & 2,394 & 2,398 & 2,489 & 1,640 & 2,153 \\
\hline & PGSUS & 3,350 & 3,302 & 0,879 & 0,925 & 1,320 & 1,481 & 1,338 & 1,062 & 1,138 & 0,477 & 1,476 & 1,099 & 1,558 & 0,479 \\
\hline & RYSAS & 1,448 & 1,464 & 2,547 & 3,120 & 3,269 & 0,660 & 0,542 & 0,983 & 0,479 & 2,283 & 0,039 & 0,504 & 2,123 & 0,814 \\
\hline & THYAO & 1,364 & 1,430 & 1,687 & 1,289 & 2,064 & 1,189 & 2,492 & 0,882 & 1,602 & 0,756 & 2,292 & 1,470 & 2,963 & 2,254 \\
\hline \multirow{2}{*}{$\underset{\mathbb{d}}{ \pm}$} & BEYAZ & 0,562 & 0,607 & 3,059 & 3,266 & 0,047 & 3,047 & 2,314 & 3,372 & 0,193 & 1,853 & 0,023 & 0,393 & 0,263 & 3,414 \\
\hline & CLEBI & 1,624 & 1,545 & 2,394 & 2,125 & 1,779 & 2,220 & 1,156 & 1,886 & 2,910 & 2,110 & 2,571 & 3,195 & 1,745 & 1,689 \\
\hline \multirow{3}{*}{$\stackrel{m}{\bar{\sigma}}}$. & PGSUS & 3,084 & 3,100 & 0,907 & 0,646 & 0,711 & 1,707 & 2,192 & 0,734 & 1,709 & 1,387 & 1,468 & 1,679 & 2,942 & 1,307 \\
\hline & RYSAS & 1,309 & 1,356 & 0,074 & 0,604 & 0,796 & 0,607 & 0,615 & 0,713 & 2,789 & 2,964 & 2,990 & 2,918 & 0,903 & 3,143 \\
\hline & THYAO & 0,819 & 0,825 & 1,235 & 0,764 & 0,958 & 1,774 & 2,654 & 0,870 & 1,646 & 0,181 & 1,401 & 1,399 & 1,733 & 0,769 \\
\hline
\end{tabular}

Entropi yönteminin dördüncü aşamasında koordinat dönüşümü yapılmış karar matrisi normalize edilmiş ve Tablo 6' da gösterilmiştir. 
Tablo 6: Entropi Normalize Karar Matrisi

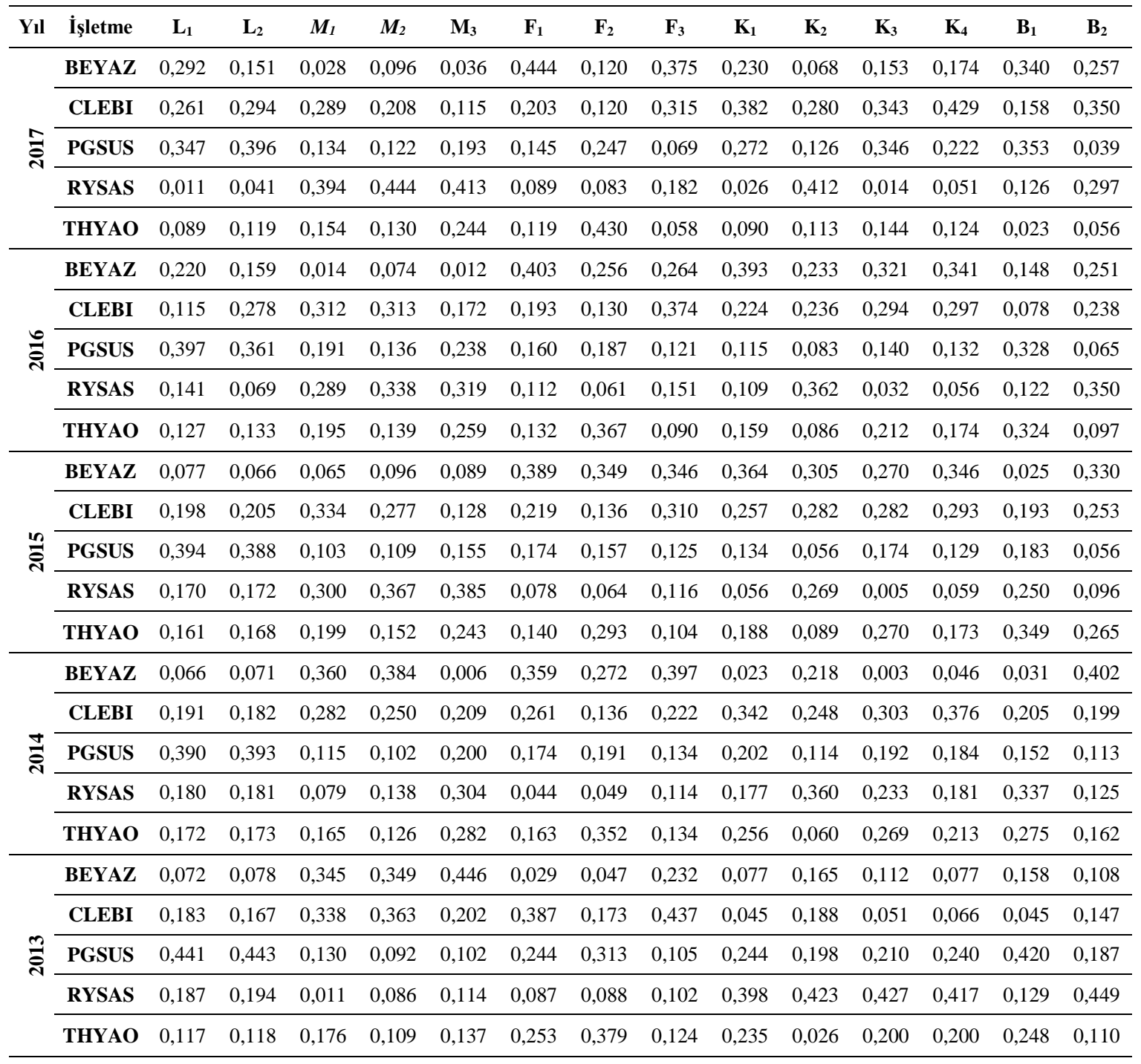

Tablo 7'de kriterlerin geliştirilmiş Entropi yöntemine göre hesaplanan entropi değerleri yer almaktadır.

Tablo 7: Değerlendirme Kriterlerinin Entropi Değerleri

\begin{tabular}{ccccccccccccccc}
\hline Yll & $\mathbf{L}_{\mathbf{1}}$ & $\mathbf{L}_{\mathbf{2}}$ & $\boldsymbol{M}_{\boldsymbol{1}}$ & $\boldsymbol{M}_{\mathbf{2}}$ & $\mathbf{M}_{\mathbf{3}}$ & $\mathbf{F}_{\mathbf{1}}$ & $\mathbf{F}_{\mathbf{2}}$ & $\mathbf{F}_{\mathbf{3}}$ & $\mathbf{K}_{\mathbf{1}}$ & $\mathbf{K}_{\mathbf{2}}$ & $\mathbf{K}_{\mathbf{3}}$ & $\mathbf{K}_{\mathbf{4}}$ & $\mathbf{B}_{\mathbf{1}}$ & $\mathbf{B}_{\mathbf{2}}$ \\
\hline $\mathbf{2 0 1 7}$ & 0,269 & 0,279 & 0,277 & 0,287 & 0,279 & 0,287 & 0,285 & 0,278 & 0,274 & 0,283 & 0,272 & 0,282 & 0,275 & 0,273 \\
\hline $\mathbf{2 0 1 6}$ & 0,297 & 0,294 & 0,283 & 0,294 & 0,282 & 0,298 & 0,293 & 0,295 & 0,297 & 0,293 & 0,288 & 0,292 & 0,294 & 0,292 \\
\hline $\mathbf{2 0 1 5}$ & 0,296 & 0,295 & 0,292 & 0,295 & 0,296 & 0,296 & 0,293 & 0,295 & 0,293 & 0,290 & 0,279 & 0,292 & 0,287 & 0,290 \\
\hline $\mathbf{2 0 1 4}$ & 0,295 & 0,296 & 0,294 & 0,296 & 0,279 & 0,291 & 0,291 & 0,297 & 0,286 & 0,292 & 0,278 & 0,292 & 0,288 & 0,298 \\
\hline $\mathbf{2 0 1 3}$ & 0,285 & 0,286 & 0,271 & 0,282 & 0,287 & 0,275 & 0,278 & 0,286 & 0,278 & 0,278 & 0,282 & 0,281 & 0,281 & 0,287 \\
\hline
\end{tabular}

Tablo 8'de kriterlerin geliştirilmiş Entropi yöntemine göre hesaplanan farklılaşma dereceleri yer almaktadır. 
Tablo 8: Değerlendirme Kriterlerinin Farklılaşma Dereceleri

\begin{tabular}{ccccccccccccccc}
\hline Yll & $\mathbf{L}_{\mathbf{1}}$ & $\mathbf{L}_{\mathbf{2}}$ & $\boldsymbol{M}_{\boldsymbol{1}}$ & $\boldsymbol{M}_{\mathbf{2}}$ & $\mathbf{M}_{\mathbf{3}}$ & $\mathbf{F}_{\mathbf{1}}$ & $\mathbf{F}_{\mathbf{2}}$ & $\mathbf{F}_{\mathbf{3}}$ & $\mathbf{K}_{\mathbf{1}}$ & $\mathbf{K}_{\mathbf{2}}$ & $\mathbf{K}_{\mathbf{3}}$ & $\mathbf{K}_{\mathbf{4}}$ & $\mathbf{B}_{\mathbf{1}}$ & $\mathbf{B}_{\mathbf{2}}$ \\
\hline $\mathbf{2 0 1 7}$ & 0,731 & 0,721 & 0,723 & 0,713 & 0,721 & 0,713 & 0,715 & 0,722 & 0,726 & 0,717 & 0,728 & 0,718 & 0,725 & 0,727 \\
\hline $\mathbf{2 0 1 6}$ & 0,703 & 0,706 & 0,717 & 0,706 & 0,718 & 0,702 & 0,707 & 0,705 & 0,703 & 0,707 & 0,712 & 0,708 & 0,706 & 0,708 \\
\hline $\mathbf{2 0 1 5}$ & 0,704 & 0,705 & 0,708 & 0,705 & 0,704 & 0,704 & 0,707 & 0,705 & 0,707 & 0,710 & 0,721 & 0,708 & 0,713 & 0,710 \\
\hline $\mathbf{2 0 1 4}$ & 0,705 & 0,704 & 0,706 & 0,704 & 0,721 & 0,709 & 0,709 & 0,703 & 0,714 & 0,708 & 0,722 & 0,708 & 0,712 & 0,702 \\
\hline $\mathbf{2 0 1 3}$ & 0,715 & 0,714 & 0,729 & 0,718 & 0,713 & 0,725 & 0,722 & 0,714 & 0,722 & 0,722 & 0,718 & 0,719 & 0,719 & 0,713 \\
\hline
\end{tabular}

Tablo 9'da kriterlerin geliştirilmiş Entropi yöntemine göre hesaplanan ağırlıkları yer almaktadir.

\section{Tablo 9: Entropi Kriter A ğırlıkları}

\begin{tabular}{|c|c|c|c|c|c|c|c|c|c|c|c|c|c|c|}
\hline Yıl & $\mathbf{L}_{1}$ & $\mathbf{L}_{2}$ & $\mathbf{M}_{1}$ & $\mathbf{M}_{2}$ & $\mathbf{M}_{3}$ & $\mathbf{F}_{1}$ & $\mathbf{F}_{2}$ & $\mathbf{F}_{3}$ & $\mathbf{K}_{1}$ & $\mathbf{K}_{2}$ & $\mathbf{K}_{3}$ & $\mathbf{K}_{4}$ & $\mathbf{B}_{1}$ & $\mathbf{B}_{2}$ \\
\hline 2017 & 0,0724 & 0,0714 & 0,0716 & 0,0706 & 0,0714 & 0,0706 & 0,0708 & 0,0714 & 0,0718 & 0,0710 & 0,0721 & 0,0710 & 0,0718 & 0,0719 \\
\hline 2016 & 0,0709 & 0,0713 & 0,0724 & 0,0713 & 0,0724 & 0,0709 & 0,0713 & 0,0711 & 0,0710 & 0,0713 & 0,0719 & 0,0715 & 0,0713 & 0,0715 \\
\hline 2015 & 0,0710 & 0,0711 & 0,0714 & 0,0711 & 0,0710 & 0,0711 & 0,0713 & 0,0711 & 0,0714 & 0,0717 & 0,0728 & 0,0714 & 0,0719 & 0,0716 \\
\hline 2014 & 0,0710 & 0,0710 & 0,0711 & 0,0709 & 0,0726 & 0,0714 & 0,0714 & 0,0708 & 0,0719 & 0,0713 & 0,0728 & 0,0713 & 0,0717 & 0,0708 \\
\hline 2013 & 0,0710 & 0,0710 & 0,0725 & 0,0714 & 0,0709 & 0,0720 & 0,0717 & 0,0710 & 0,0718 & 0,0717 & 0,0714 & 0,0714 & 0,0714 & 0,0708 \\
\hline
\end{tabular}

Tablo 10'da kriterlerin TOPSIS yönteminde elde edilen normalize karar matrisinin entropi ağırlıkları ile ağırlıklandırılmış hali yer almaktadır.

\section{Tablo 10: Entropi Ăgırlıklı Karar Matrisi}

\begin{tabular}{cccccccccccccccccc}
\hline Yll İșletme & $\mathbf{L}_{\mathbf{1}}$ & $\mathbf{L}_{\mathbf{2}}$ & $\boldsymbol{M}_{\mathbf{1}}$ & $\boldsymbol{M}_{\mathbf{2}}$ & $\mathbf{M}_{\mathbf{3}}$ & $\mathbf{F}_{\mathbf{1}}$ & $\mathbf{F}_{\mathbf{2}}$ & $\mathbf{F}_{\mathbf{3}}$ & $\mathbf{K}_{\mathbf{1}}$ & $\mathbf{K}_{\mathbf{2}}$ & $\mathbf{K}_{\mathbf{3}}$ & $\mathbf{K}_{\mathbf{4}}$ & $\mathbf{B}_{\mathbf{1}}$ & $\mathbf{B}_{\mathbf{2}}$ \\
\hline BEYAZ & 0,0382 & 0,0253 & 0,0448 & 0,0602 & 0,0011 & 0,0622 & 0,0203 & 0,0475 & 0,0287 & 0,0109 & 0,0103 & 0,0132 & 0,0454 & $-0,0033$ \\
\hline CLEBI & 0,0356 & 0,0382 & 0,0372 & 0,0439 & 0,0129 & 0,0252 & 0,0204 & 0,0411 & 0,0547 & 0,0375 & 0,0483 & 0,0648 & 0,0227 & 0,0171 \\
\hline PGSUS & 0,0426 & 0,0474 & 0,0417 & 0,0564 & 0,0246 & 0,0164 & 0,0336 & 0,0152 & 0,0359 & 0,0182 & 0,0488 & 0,0230 & 0,0469 & $-0,0510$ \\
\hline RYSAS & 0,0152 & 0,0155 & 0,0341 & 0,0095 & 0,0574 & 0,0078 & 0,0164 & 0,0271 & $-0,0062$ & 0,0540 & $-0,0175$ & $-0,0117$ & 0,0187 & 0,0053 \\
\hline THYAO & 0,0216 & 0,0225 & 0,0411 & 0,0553 & 0,0321 & 0,0125 & 0,0528 & 0,0140 & 0,0047 & 0,0165 & 0,0083 & 0,0031 & 0,0059 & $-0,0473$ \\
\hline BEYAZ & 0,0323 & 0,0253 & 0,0492 & 0,0638 & 0,0030 & 0,0630 & 0,0361 & 0,0372 & 0,0658 & 0,0260 & 0,0320 & 0,0489 & 0,0153 & $-0,0112$ \\
\hline CLEBI & 0,0247 & 0,0382 & 0,0351 & 0,0263 & 0,0251 & 0,0234 & 0,0197 & 0,0539 & 0,0182 & 0,0270 & 0,0237 & 0,0358 & 0,0020 & $-0,0140$ \\
\hline PGSUS & 0,0449 & 0,0473 & 0,0408 & 0,0541 & 0,0342 & 0,0173 & 0,0271 & 0,0156 & $-0,0128$ & $-0,0115$ & $-0,0226$ & $-0,0130$ & 0,0490 & $-0,0518$ \\
\hline RYSAS & 0,0266 & 0,0154 & 0,0362 & 0,0223 & 0,0454 & 0,0080 & 0,0106 & 0,0201 & $-0,0145$ & 0,0586 & $-0,0553$ & $-0,0356$ & 0,0102 & 0,0103 \\
\hline THYAO & 0,0256 & 0,0225 & 0,0406 & 0,0537 & 0,0371 & 0,0118 & 0,0505 & 0,0109 & $-0,0004$ & $-0,0108$ & $-0,0010$ & $-0,0004$ & 0,0483 & $-0,0447$ \\
\hline
\end{tabular}


Optimum Ekonomi ve Yönetim Bilimleri Dergisi, Cilt 7, Sayı 1- http://dergipark.gov.trloptimum Sakarya ve Aksu - Ulaşım Sektöründeki İşletmelerin Finansal Performanslarının Geliştirilmiş Entropi Temelli TOPSIS Yöntemi ile Değerlendirilmesi

Tablo 10-devam: Entropi Ağırlıklı Karar Matrisi

\begin{tabular}{|c|c|c|c|c|c|c|c|c|c|c|c|c|c|c|c|}
\hline \multirow{4}{*}{$\stackrel{n}{\stackrel{2}{*}}$} & BEYAZ & 0,0128 & 0,0074 & 0,0434 & 0,0554 & 0,0111 & 0,0556 & 0,0503 & 0,0478 & 0,0580 & 0,0420 & 0,0360 & 0,0543 & $-0,0165$ & 0,0499 \\
\hline & PGSUS & 0,0537 & 0,0559 & 0,0423 & 0,0537 & 0,0210 & 0,0239 & 0,0211 & 0,0188 & 0,0078 & 0,0123 & 0,0112 & 0,0050 & 0,0185 & $-0,0229$ \\
\hline & RYSAS & 0,0249 & 0,0234 & 0,0368 & 0,0212 & 0,0552 & 0,0097 & 0,0069 & 0,0175 & $-0,0091$ & 0,0377 & $-0,0324$ & $-0,0109$ & 0,0332 & $-0,0124$ \\
\hline & THYAO & 0,0236 & 0,0228 & 0,0397 & 0,0483 & 0,0340 & 0,0189 & 0,0418 & 0,0160 & 0,0197 & 0,0162 & 0,0359 & 0,0150 & 0,0551 & 0,0328 \\
\hline \multirow{3}{*}{$\stackrel{ \pm}{\bar{\sim}}$} & CLEBI & 0,0267 & 0,0245 & 0,0365 & 0,0358 & 0,0302 & 0,0362 & 0,0223 & 0,0285 & 0,0539 & 0,0350 & 0,0452 & 0,0619 & 0,0151 & 0,0177 \\
\hline & PGSUS & 0,0551 & 0,0571 & 0,0427 & 0,0564 & 0,0288 & 0,0278 & 0,0286 & 0,0116 & 0,0219 & 0,0202 & 0,0240 & 0,0096 & 0,0004 & $-0,0034$ \\
\hline & RYSAS & 0,0252 & 0,0243 & 0,0440 & 0,0514 & 0,0435 & 0,0153 & 0,0124 & 0,0078 & 0,0161 & 0,0474 & 0,0318 & 0,0089 & 0,0516 & $-0,0005$ \\
\hline \multirow{4}{*}{ 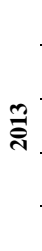 } & CLEBI & 0,0272 & 0,0247 & 0,0340 & 0,0212 & 0,0271 & 0,0413 & 0,0252 & 0,0614 & 0,0063 & 0,0291 & 0,0043 & 0,0170 & 0,0077 & 0,0076 \\
\hline & PGSUS & 0,0537 & 0,0554 & 0,0440 & 0,0624 & 0,0140 & 0,0338 & 0,0416 & 0,0102 & 0,0330 & 0,0300 & 0,0274 & 0,0333 & 0,0556 & 0,0157 \\
\hline & RYSAS & 0,0276 & 0,0277 & 0,0497 & 0,0634 & 0,0156 & 0,0255 & 0,0151 & 0,0098 & 0,0538 & 0,0494 & 0,0590 & 0,0500 & 0,0184 & 0,0686 \\
\hline & THYAO & 0,0204 & 0,0192 & 0,0418 & 0,0599 & 0,0186 & 0,0343 & 0,0494 & 0,0132 & 0,0318 & 0,0151 & 0,0260 & 0,0296 & 0,0336 & 0,0002 \\
\hline
\end{tabular}

Analize dahil edilen 2013-2017 arasındaki y1llara ait pozitif ideal (A*) ve negatif ideal (A`) çözüm setleri aşağıdaki gibidir:

$\mathrm{A}^{*}{ }_{2017}=\{0,043 ; 0,047 ; 0,034 ; 0,010 ; 0,057 ; 0,062 ; 0,053 ; 0,047 ; 0,055 ; 0,054 ; 0,049 ; 0,065 ; 0,047 ; 0,017\}$

$\mathrm{A}^{-}{ }_{2017}=\{0,015 ; 0,015 ; 0,045 ; 0,060 ; 0,001 ; 0,008 ; 0,016 ; 0,014 ;-0,006 ; 0,011 ;-0,018 ;-0,012 ; 0,006 ;-0,051\}$

$\mathrm{A}^{*}{ }_{2016}=\{0,045 ; 0,047 ; 0,035 ; 0,022 ; 0,045 ; 0,063 ; 0,051 ; 0,054 ; 0,066 ; 0,059 ; 0,032 ; 0,049 ; 0,049 ; 0,010\}$

$\mathrm{A}^{-} 2016=\{0,025 ; 0,015 ; 0,049 ; 0,064 ; 0,003 ; 0,008 ; 0,011 ; 0,011 ;-0,014 ;-0,012 ;-0,055 ;-0,036 ; 0,002 ;-0,052\}$

$\mathrm{A}^{*}{ }_{2015}=\{0,054 ; 0,056 ; 0,036 ; 0,021 ; 0,055 ; 0,056 ; 0,050 ; 0,048 ; 0,058 ; 0,042 ; 0,039 ; 0,054 ; 0,055 ; 0,050\}$

$\mathrm{A}^{-}{ }_{2015}=\{0,013 ; 0,007 ; 0,043 ; 0,055 ; 0,011 ; 0,010 ; 0,007 ; 0,016 ;-0,009 ; 0,012 ;-0,032 ;-0,011 ;-0,016 ;-0,023\}$

$\mathrm{A}^{*}{ }_{2014}=\{0,055 ; 0,057 ; 0,034 ; 0,017 ; 0,044 ; 0,046 ; 0,047 ; 0,062 ; 0,054 ; 0,047 ; 0,045 ; 0,062 ; 0,052 ; 0,068\}$

$\mathrm{A}^{-} 2014=\{0,009 ; 0,007 ; 0,044 ; 0,056 ; 0,002 ; 0,015 ; 0,012 ; 0,008 ;-0,019 ; 0,014 ;-0,013 ;-0,028 ;-0,033 ;-0,003\}$

$\mathrm{A}^{*}{ }_{2013}=\{0,054 ; 0,055 ; 0,034 ; 0,021 ; 0,059 ; 0,041 ; 0,049 ; 0,061 ; 0,054 ; 0,049 ; 0,059 ; 0,050 ; 0,056 ; 0,069\}$

$\mathrm{A}^{-}{ }_{2013}=\{0,016 ; 0,015 ; 0,050 ; 0,063 ; 0,014 ; 0,023 ; 0,010 ; 0,010 ; 0,006 ; 0,015 ; 0,004 ; 0,017 ; 0,008 ;-0,0003\}$

Pozitif ideal $\left(\mathrm{A}^{*}\right)$ ve negatif ideal $\left(\mathrm{A}^{-}\right)$çözüm setinin oluşturulmasının ardından her bir alternatifin pozitif ideal $\left(\mathrm{Si}^{*}\right)$ ve negatif ideal $\left(\mathrm{Si}^{-}\right)$çözümden uzaklığı hesaplanmıştır. Son olarak işletmelerin pozitif ideal çözüme olan göreli yakınlığı $\left(\mathrm{C}_{\mathrm{i}}^{*}\right)$ belirlenerek finansal performansları açısından sıralamaları yapılmış ve sonuçlar Grafik 1'de gösterilmiştir. 


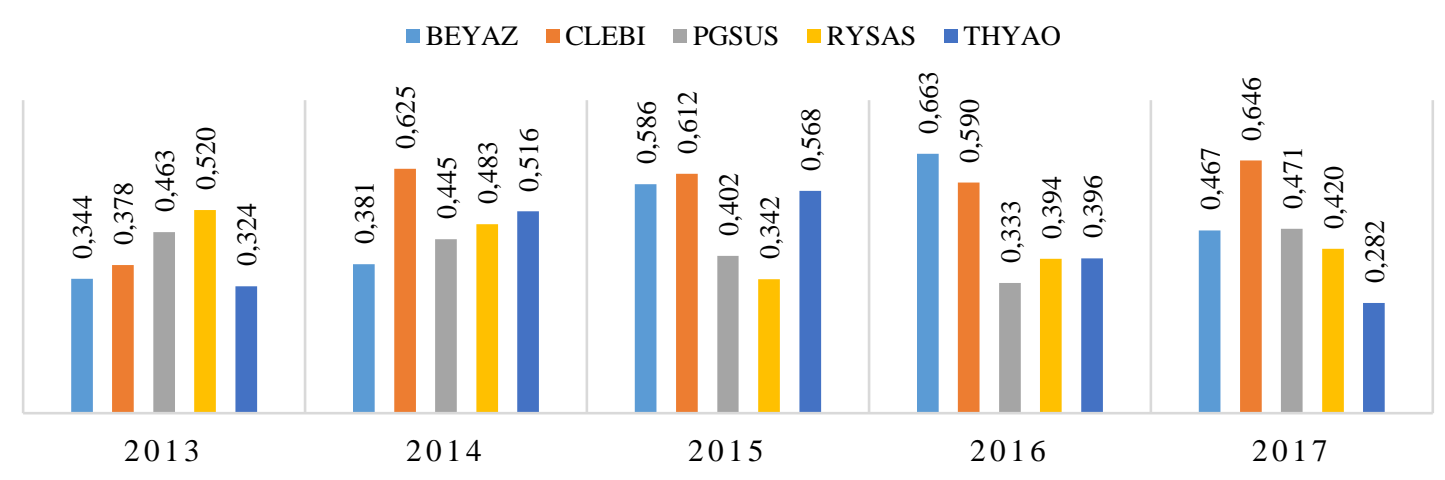

Grafik 1: TOPSIS Sonuçları

TOPSIS yöntemi sonucunda Grafik 1'de ulaş1lan sonuçlara göre 2013 yılından 2017 yılına kadar en başarılı firmalar sırasıyla RYSAS, CLEBI, CLEBI, BEYAZ ve CLEBI olmuştur. Finansal açıdan en başarısız olan işletmeler ise sırasıyla THYAO, BEYAZ, RYSAS, PGSUS ve THYAO olmuştur. TOPSIS yöntemi ile elde edilen işletmelerin finansal performans sıralamalarının yıllar içerisindeki seyri Tablo 11'de gösterilmektedir.

Tablo 11: Finansal Performans Siralamasının Seyri

\begin{tabular}{cccccc}
\hline İșletme/Yıl & $\mathbf{2 0 1 3}$ & $\mathbf{2 0 1 4}$ & $\mathbf{2 0 1 5}$ & $\mathbf{2 0 1 6}$ & $\mathbf{2 0 1 7}$ \\
\hline BEYAZ & 4 & 5 & 2 & 1 & 3 \\
\hline CLEBI & 3 & 1 & 1 & 2 & 1 \\
\hline PGSUS & 2 & 4 & 4 & 5 & 2 \\
\hline RYSAS & 1 & 3 & 5 & 4 & 4 \\
\hline THYAO & 5 & 2 & 3 & 3 & 5 \\
\hline
\end{tabular}

Tablo 11'e göre RYSAS 2013 yılı sıralamasında en başarılı işletme iken sonraki yıllarda finansal performansı düşmüştür. BEYAZ'ın finansal durumu ise RYSAS'ın tersine 2013 ve 2014 yıllarında son siralarda yer alırken sonraki yıllarda finansal performans siralamasında ilk sıralara yükselmiştir. Tablo 11'de CLEBI'nin 2013 yılındaki düşük finansal performansının ardından sonraki yıllarda 1 . ve 2. sirada yer aldığ 1 görülmektedir. THYAO ve PGSUS'un finansal performansı 2013-2017 yılları arasında dalgalı bir seyir izlemiştir. THYAO'nun finansal performansının 2. ve 3. siralarda yer aldığ 2014, 2015, 2016 yıllarında PGSUS 4. ve 5. sirada yer alan işletme olmuştur. PGSUS'un finansal performansının 2. sırada yer aldığı 2013 ve 2017 yıllarında ise THYAO'nun finansal performansının son sırada yer alması dikkat çekmektedir.

Tablo 12: İşsetmelerin Hisse Getirileri (\%)

\begin{tabular}{cccccc}
\hline İșletme/Yıl & $\mathbf{2 0 1 2 - 2 0 1 3}^{*}$ & $\mathbf{2 0 1 3 - 2 0 1 4}^{*}$ & $\mathbf{2 0 1 4 - 2 0 1 5}^{*}$ & $\mathbf{2 0 1 5 - 2 0 1 6}^{*}$ & $\mathbf{2 0 1 6 - 2 0 1 7}^{*}$ \\
\hline BEYAZ & $-53,87$ & $-0,56$ & 89,89 & 142,01 & 1030,04 \\
\hline CLEBI & $-40,48$ & 138,53 & 38,42 & $-29,65$ & 69,6 \\
\hline PGSUS & $93,60 * *$ & $-8,68$ & $-47,03$ & $-19,42$ & 138,87 \\
\hline RYSAS & $-9,72$ & 23,08 & $-11,84$ & 21,54 & 62,03 \\
\hline THYAO & 20,27 & 49,53 & $-23,26$ & $-32,21$ & 213,17 \\
\hline
\end{tabular}

*Hisse getirileri yılların 31 Aralık tarihleri arasındaki kapanış değerlerinin yüzde değişimini göstermektedir.

**PGSUS'un hisse getirisi 26.04.2013-31.12.2013 tarihleri arasındaki getirisidir. 
TOPSIS yöntemi ile elde edilen finansal performans sıralamaları işletmelerin hisse getirileri sıralamaları ile karşılaştırılmıştır. Tablo 12'de işletmelerin yıllık hisse getirileri, Tablo 13 'te de işletmelerin finansal performans sıralamaları ile hisse getiri sıralamaları karşılaştırmalı olarak verilmiştir.

Tablo 13: İşletmelerin Finansal Performans ve Hisse Getiri Sıralamalarının

Karşılaştırılması

\begin{tabular}{lcccccccccc}
\hline İşletme/Yıl & $\mathbf{2 0 1 3}$ & Hisse Getiri & $\mathbf{2 0 1 4}$ & Hisse Getiri & $\mathbf{2 0 1 5}$ & Hisse Getiri & $\mathbf{2 0 1 6}$ & Hisse Getiri & 2017 & Hisse Getiri \\
\hline BEYAZ & 4 & 5 & 5 & 4 & 2 & 1 & 1 & 1 & 3 & 1 \\
\hline CLEBI & 3 & 4 & 1 & 1 & 1 & 2 & 2 & 4 & 1 & 4 \\
\hline PGSUS & 2 & 1 & 4 & 5 & 4 & 5 & 5 & 3 & 2 & 3 \\
\hline RYSAS & 1 & 3 & 3 & 3 & 5 & 3 & 4 & 2 & 4 & 5 \\
\hline THYAO & 5 & 2 & 2 & 2 & 3 & 4 & 3 & 5 & 5 & 2 \\
\hline
\end{tabular}

Tablo 13'te 2013 yılında TOPSIS yönteminde en başarılı olarak belirlenen RYSAS'ın negatif getiriye sahip olduğu tespit edilirken, finansal performans sıralamasında beşinci sırada yer alan THYAO'nun pozitif hisse getirisine sahip olduğu ve hisse getirisi bakımından ikinci sırada yer aldığı görülmüştür. 2013 yılı haricindeki diğer yıllarda finansal performansı birinci sırada yer alan işletmelerin pozitif hisse getirisine sahip olduğu tespit edilmiştir. 2014, 2015, 2016 yıllarında başarısız olarak tespit edilen işletmelerin (BEYAZ, RYSAS, PGSUS) hisse getirilerinin negatif olduğu tespit edilmiş̧tir.

İşletmelerin TOPSIS yöntemi ile elde edilen finansal performans sıralamaları ile hisse getiri sıralamaları karşılaştırıldığında finansal açıdan başarılı olarak tespit edilen işletmelerin her zaman en yüksek hisse getirisine sahip olmadığı anlaşılmaktadır.

\section{SONUÇ}

Bu çalışmada ulaşım sektöründe faaliyet gösteren ve BIST'te işlem gören beş işletmenin 20132017 yılları arasında finansal performanslarının TOPSIS yöntemi ile değerlendirilip karşılaştırılması amaçlanmaktadır. TOPSIS yöntemi farklı değerlendirme kriterlerini ortak bir paydada bir araya getirerek karar vericilere objektif bir değerleme imkanı tanımaktadır. Çalışmada işletmelerin finansal performanslarını yansıtan on dört farklı finansal oran (cari oran, asit test oran1, finansal kaldıraç oran1, toplam borç/özsermaye oranı, maddi duran varlık/özsermaye oranı, aktif devir hızı, alacak devir hızı, özsermaye devir hızı, aktif karlılık oran1, esas faaliyet kar marj1, net kar marj1, özsermaye karlılık oran1, aktif büyüme oranı, esas faaliyet karı büyüme oranı) değerlendirme kriteri olarak seçilmiştir. İşletmelerin finansal performanslarının değerlendirilmesinde kullanılan finansal oranların ağırlıkları geliştirilmiş Entropi yönteminden yararlanılarak hesaplanmıştır.

TOPSIS yöntemi ile elde edilen sonuçlara göre 2013 yılından 2017 yılına kadar en başarılı firmalar sırasıyla RYSAS, CLEBI, CLEBI, BEYAZ ve CLEBI olmuştur. Finansal açıdan en başarısız olan işletmeler ise sırasıyla THYAO, BEYAZ, RYSAS, PGSUS ve THYAO olmuştur.

2013 yılının finansal performans bakımından en başarılı işletmesi RYSAS iken, diğer yıllarda birinci sıra BEYAZ ile CLEBI arasında değişmiştir. RYSAS'ın finansal performansı beş ulaşım işletmesi arasında 2013 yılından sonra gerilemiştir. 2013 ve 2014 yıllarında finansal performans sıralamasında son sıralarda yer alan BEYAZ 2015 ve 2016 yıllarının en başarılı iki firması arasında yer almıştır. Finansal performans sıralamasında PGSUS ve THYAO'nun 
finansal performanslarının birbirine zıt yönde hareket ettiği diğer bir ifadeyle PGSUS finansal performans sıralamasında yükselirken, THYAO’nun düştüğü görülmüştür.

Çalışmada TOPSIS yöntemi ile yapılan finansal performans sıralamasının işletmelerin hisse getirilerini yansıtıp yansıtmadığı değerlendirilmiştir. Çalışmanın sonucunda 2013 yılında TOPSIS yönteminde en başarılı olarak belirlenen RYSAS'ın negatif getiriye sahip olduğu tespit edilirken, finansal performans sıralamasında beşinci sırada yer alan THYAO'nun pozitif hisse getirisine sahip olduğu, 2014, 2015 ve 2016 yıllarında ise başarısız olduğu tespit edilen işletmelerin hisse getirilerinin negatif, başarılı olduğu belirlenen işletmelerin de hisse getirilerinin pozitif olduğu tespit edilmiştir.

İşletmelerin TOPSIS yöntemi ile elde edilen finansal performans sıralamaları ile hisse getiri sıralamaları karşılaştırıldığında finansal açıdan başarılı olarak tespit edilen işletmelerin her zaman en yüksek hisse getirisine sahip olmadığı anlaşılmaktadır. Bu durum davranışsal finans bağlamında, yatırımcıların hisse senetlerine yatırım kararlarında her zaman rasyonel olmadıkları sonucunu destekler niteliktedir.

İşletmelerin finansal performans sıralamaları, işletmelerin faaliyet gösterdikleri sektördeki işletmeler arasında kendilerini konumlandırabilmesi ve bu işletmeler ile rekabet edebilmesi noktasında oldukça önemlidir. Ulaşım sektöründe faaliyet gösteren Türkiye'nin en büyük 500 işletmesi içerisinde yer alan ve BİST'te işlem gören işletmelerin finansal performansların değerlendirildiği bu çalışmada ulaşılan sonuçların ulaşım sektöründeki karar vericilere ve mevcut ya da potansiyel yatırımcılara alacakları finansman ve yatırım kararlarında yardımcı olacağı düşünülmektedir.

\section{KAYNAKÇA}

Akgün, M. ve Soy Temür, A. (2016). BIST ulaştırma endeksine kayıtlı şirketlerin finansal performanslarının TOPSIS yöntemi ile değerlendirilmesi. Uluslararası Yönetim İktisat ve İşletme Dergisi, 30, 173-186.

Ayaydın, H., Durmuş, S. ve Pala, F. (2017). Gri ilişkisel analiz yöntemiyle Türk lojistik firmalarında performans ölçümü. Gümüşhane Üniversitesi Sosyal Bilimler Dergisi, 8(21), 76-94.

Ayçin, E. (2018). BIST menkul kıymet yatırım ortaklıkları endeksinde (XYORT) yer alan işletmelerin finansal performanslarının entropi ve gri ilişkisel analiz bütünleşik yaklaşımı ile değerlendirilmesi. Dokuz Eylül Üniversitesi İktisadi ve İdari Bilimler Fakültesi Dergisi, 33(2), 595-622.

Aytekin, S. ve Erol, A. (2018). Finansal performans kurumsal sürdürülebilirlik performansının temel belirleyicisi midir? BIST sürdürülebilirlik endeksinde ARAS yöntemi ile bir uygulama. Uluslararası İktisadi ve İdari İncelemeler Dergisi, 17. UİK Özel Sayıs1, 869-886.

Başdeğirmen, A. ve Iş̧1dak, B. (2018). Ulaştırma sektöründe faaliyet gösteren işletmelerin performanslarının gri ilişkisel analiz ile değerlendirilmesi. Süleyman Demirel Üniversitesi İktisadi ve İdari Bilimler Fakültesi Dergisi, 23(2), 563-577.

Başdeğirmen, A. ve Tunca, M.Z.(2017). Lojistik sektöründe faaliyet gösteren işletmelerin finansal performanslarının gri ilişkisel analiz ile değerlendirilmesi. Süleyman Demirel Üniversitesi İktisadi ve İdari Bilimler Fakültesi Dergisi, 22(2), 327-340.

Chang, Y. H., Cheng, C. H. \& Wang, T.C. (2003). Performance evaluation of international airports in the region of East Asia. Proceedings of

Ege, İ. ve Yaman, S. (2018). TOPSIS ve MOORA yöntemleri ile ölçülen finansal performansın pay getirilerine etkisi: BIST çimento beton işletmeleri üzerine bir panel veri uygulaması. Al-Farabi Uluslararası Sosyal Bilimler Dergisi, 2(1), 75-96.

Erdoğan, H. T. (2016). Ulaşım hizmetlerinin ekonomik kalkınma üzerine etkisi. İstanbul Gelişim Üniversitesi Sosyal Bilimler Dergisi, 3(1), 187-215.

Esbouei, S. K., Ghadikolaei, A. S., \& Antucheviciene, J. (2014). Using FANP and Fuzzy VIKOR for ranking manufacturing companies based on their financial performance. Economic Computation \& Economic Cybernetics Studies \& Research, 48(3), 287-308. 
Feng, C. M. \& Wang, R. T. (2000). Performance evaluation for airlines including the consideration of financial ratios. Journal of Air Transport Management, 6(3), 133-142.

Gümüş, U. T., Öziç, H. C., Evlimoğlu, U. ve Sezer, D. (2018). Ulaşım sektöründeki firmaların AHP ve TOPSIS yöntemi ile değerlendirme sonuçlarının borsa getirileri ile analizi.

Hwang, C.L. \& Yoon, K. (1981). Multiple attributes decision making methods and applications, Springer, Berlin Heidelberg.

Jahan, A. \& Edwards, K. L. (2015). A state-of-the-art survey on the influence of normalization techniques in ranking: Improving the materials selection process in engineering design. Materials and Design, 65, 335-342.

Kendirli, S. ve Kaya, A. (2016). BIST ulaştırma endeksinde yer alan firmaların mali performanslarının ölçülmesi ve TOPSIS yönteminin uygulanması. Manas Sosyal Araşttrmalar Dergisi, 5(1), 34-63.

Kiracı, K. ve Bakır, M. (2018). Entropi temelli TOPSIS yöntemiyle iş modeline göre havayolu firmalarının finansal performanslarının analizi. 17. Uluslararası Katılımlı Işsletmecilik Kongresi Bildiriler Kitabı, 1063-1069.

Korkmaz, O. ve Uygurtürk, H. (2010). Denizyolu taşımacıllı̆ı işletmelerinin finansal performanslarının TOPSIS yöntemi ile belirlenmesi, Mali Ufuklar Dergisi, 2, 35-54.

Liao, H., Wu, X. \& Herrera, F. (2018). DNBMA: A double normalization-based multi-aggregation method. Information processing and management of uncertainty in knowledge-based systems. applications: 17th International Conference, IPMU 2018, Cádiz, Spain, June 11-15, 2018, Proceedings.

Ömürbek, V. ve Kınay, B. (2013). Havayolu taşımacılığı sektöründe TOPSIS yöntemiyle finansal performans değerlendirmesi. Süleyman Demirel Üniversitesi İktisadi ve İdari Bilimler Fakültesi Dergisi, 18(3), 343-363.

Özbek, A. ve Demirkol, İ. (2018). Lojistik sektöründe faaliyet gösteren işletmelerin SWARA ve GİA yöntemleri ile analizi. Kırıkale Üniversitesi Sosyal Bilimler Dergisi, 8(1), 71-86.

Salabun, W. (2013). Normalization of attribute values in TOPSIS method. Publisher: CREATIVETIME, 180-186.

Vafaei, N., Ribeiro, R. A. \& Camarinha-Matos, L. M. (2015). Importance of data normalization in decision making: case study with TOPSIS method. The 1st Int. Conference on Decision Support Systems Technologies An Ewg-Dss Conference. Belgrade, Serbia, May 27-29, 2015.

Vafaei, N., Ribeiro, R. A. \& Camarinha-Matos, L. M. (2016). Normalization techniques for multi-criteria decision making: Analytical hierarchy process case study. In doctoral conference on computing, electrical and industrial systems (pp. 261-269). Springer, Cham.

Wang, Y. (2008). Applying FMCDM to evaluate financial performance of domestic airlines in Taiwan. Expert Systems with Applications, 34, 1837-1845.

Wang, Y. (2014). The evaluation of financial performance for Taiwan container shipping companies by fuzzy TOPSIS. Applied Soft Computing, 22, 28-35.

Yavuz, H. ve Öztel, A. (2017). Entropi tabanlı COPRAS yöntemi ile ölçek bazında finansal performans analizi: Bilgi ve iletişim sektöründe bir uygulama. Uluslararası Ekonomi Araştırmaları ve Finansal Piyasalar Kongresi Bildiriler Kitabl, 122-141.

Yıldırım, N. (2018). Lojistik işletmelerinde risk yönetimi ve finansal performans analizi: BİST'de bir uygulama. Yayınlanmış yüksek lisans tezi, Balıkesir Üniversitesi Sosyal Bilimler Enstitüsü, Balıkesir.

Zhang, X., Wang, C., Li, E. \& Xu, C. (2014). Assessment model of ecoenvironmental vulnerability based on improved entropy weight method. The Scientific World Journal, DOI: http://dx.doi.org/10.1155/2014/797814. 


\section{Extended Summary}

\section{Financial Performance Ranking of Transportation Companies with TOPSIS Based on Improved Entropy Method}

The transportation sector plays a significant role in achieving economic development for countries. Therefore, the financial and operational performance of the companies operating in the transportation sector are significant for the countries in which transportation companies operate. The competition among the companies operating in the transportation sector has increased more with the rapid increase in the significance of the transportation sector in the world market due to globalization. The international competition has been increasing in recent global economic world, because of that it is possible for companies to have the competitive advantage by controlling their costs and improving their financial performance. To improve financial performance of companies is tied to evaluating their financial performance. The evaluation of the financial performance of companies operating in the transportation sector, which has a great importance for the countries, is significant for the employees, existing and potential investors and the companies establishing in future in transportation sector. Moreover, evaluating the financial performance of companies which are representatives of the transportation sector, has a significant impact on the national economy, from a multidimensional perspective supports the financial planning of these companies. In this context, the study is expected to contribute to the transportation sector, companies that operate in this sector and existing and potential investors about their investment decisions in transportation sector.

This study aims to evaluate and compare financial performances of five transportation companies (BEYAZ, CLEBI, PGSUS, RYSAS, THYAO) which are publicly traded and between Turkey's largest 500 companies (Capital-2016) between 2013 and 2017 years. Another purpose of this study is to determine whether the financially successful companies have the highest stock returns by comparing the financial performance rankings with the stock return rankings of the companies.

Several financial ratios that are related with companies' liquidity, financial, operating, profitability and growth structures are used to measure financial performance of the five transportation companies in this study. The financial ratios used in this study are current, quick, financial leverage, total debt to equity, tangible assets to equity, total asset turnover, receivables turnover, equity turnover, return on asset, operating margin, net profit margin, return on equity, total asset growth and operating profit growth ratios. These financial ratios of the companies for 2013 and 2017 are obtained from Finnet Analiz Expert database.

Multi criteria decision making methods increase reliability of financial analysis. Therefore, TOPSIS (Technique for Order Preference by Similarity to Ideal Solution) method that is one of the multi criteria decision making methods is used to evaluate and rank the financial performances of five transportation companies in this study. The TOPSIS method provides the opportunity to evaluate different financial performance indicators simultaneously in order to evaluate and compare the financial performance of companies. The importance (weights) of the financial ratios used as an evaluation criterion in the TOPSIS method is determined by using the improved entropy method. In the original entropy method, natural logarithm function is used to calculate entropy values for the criteria. If the decision matrix for the decision problem has zero or negative values, it is not possible to perform logarithmic calculations. To solve this problem, Zhang, Wang, Li and Xu (2014) developed the improved entropy method using the Z-score standardization transformation.

According to the results obtained by TOPSIS method, the most successful companies from 2013 to 2017 are RYSAS, CLEBI, CLEBI, BEYAZ and CLEBI respectively. The most 
financially unsuccessful companies from 2013 to 2017 are THYAO, BEYAZ, RYSAS, PGSUS and THYAO respectively. While RYSAS is the most successful company in terms of financial performance in 2013, BEYAZ and CLEBI are ranked as the first on financial performance ranking in other years. The financial performance of RYSAS declined among the five transportation companies after 2013. BEYAZ which is ranked as the last in the financial performance ranking in 2013 and 2014 is among the two most financially successful companies in 2015 and 2016. In the financial performance ranking, PGSUS and THYAO's financial performance moves in opposite direction, in other words, while PGSUS rises in the financial performance ranking, THYAO falls.

In this study, it is evaluated whether the financial performance ranking made by TOPSIS method reflects the stock returns of the companies. As a result of the study, it is determined that RYSAS, which is determined to be the most successful company in TOPSIS method in 2013, has negative returns, while THYAO is ranked as the fifth in the financial performance ranking, has positive stock returns. Financially unsuccessful companies in 2014, 2015 and 2016 have negative stock returns, and successful companies have positive stock returns.

In conclusion, comparison of financial performance rankings obtained by TOPSIS method with the stock return rankings of the companies demonstrates that the companies identified as financially successful do not always have the highest stock return. This supports that investors are not always rational in their decisions to invest in stocks in the context of behavioral finance. 
Optimum Journal of Economics and Management Sciences, Vo1. 7, No. 1- http://dergipark.gov.trloptimum Sakarya and Aksu - Financial Performance Ranking of Transportation Companies with TOPSIS Based on Improved Entropy Method 